\title{
An Artificial Neural Networks Model for Predicting Permeability Properties of Nano Silica-Rice Husk Ash Ternary Blended Concrete
}

\author{
Alireza Najigivi ${ }^{1), *}$, Alireza Khaloo²), Azam Iraji zad ${ }^{1)}$, and Suraya Abdul Rashid ${ }^{3)}$
}

(Received November 20, 2012, Accepted March 21, 2013)

\begin{abstract}
In this study, a two-layer feed-forward neural network was constructed and applied to determine a mapping associating mix design and testing factors of cement-nano silica (NS)-rice husk ash ternary blended concrete samples with their performance in conductance to the water absorption properties. To generate data for the neural network model (NNM), a total of 174 field cores from 58 different mixes at three ages were tested in the laboratory for each of percentage, velocity and coefficient of water absorption and mix volumetric properties. The significant factors (six items) that affect the permeability properties of ternary blended concrete were identified by experimental studies which were: (1) percentage of cement; (2) content of rice husk ash; (3) percentage of $15 \mathrm{~nm}$ of $\mathrm{SiO}_{2}$ particles; (4) content of NS particles with average size of $80 \mathrm{~nm}$; (5) effect of curing medium and (6) curing time. The mentioned significant factors were then used to define the domain of a neural network which was trained based on the Levenberg-Marquardt back propagation algorithm using Matlab software. Excellent agreement was observed between simulation and laboratory data. It is believed that the novel developed NNM with three outputs will be a useful tool in the study of the permeability properties of ternary blended concrete and its maintenance.
\end{abstract}

Keywords: artificial neural networks, permeability, nano silica, rice husk ash, ternary blended concrete.

\section{Introduction}

Concrete is a man-made material produced by the proper mixing of cement, coarse aggregate, fine aggregate plus an adequate and controlled amount of water. It is the most consumed worldwide material after water due to its extensive usage in most of structural applications. The rapid growth of construction and buildings in developing countries in addition of vast formation of waste byproducts playing high role to concrete makers in creating sustainable product (Jamil et al. 2009). Therefore, utilization of mineral or artificial waste materials in concrete can give an efficient solution to disposal difficulty, sustainable development and moderating the cost of concrete structures.

Experience has revealed that by controlling some factors of the fresh concrete, such as the amount of cement, the water/cement ratios, dosage of admixtures in particular

\footnotetext{
${ }^{1)}$ Institute for Nanoscience \& Nanotechnology (INST), Sharif University of Technology, Tehran, Iran. *Corresponding Author; E-mail: najigivi@sharif.ir ${ }^{2)}$ Center of Excellence in Structure \& Earthquake Engineering, Sharif University of Technology, Tehran, Iran.

${ }^{3)}$ Department of Chemical and Environmental Engineering, Faculty of Engineering, Universiti Putra Malaysia, Selangor, Malaysia.

Copyright ( $\odot$ The Author(s) 2013. This article is published with open access at Springerlink.com
}

limits the long-term properties of the cement based concrete can be improved. On the other hand, concrete mix design involves complex issues, and the accurate ways of performing its design can be achieved with expert information and experience (Yeh et al. 1993).

It is worth mentioning that the permeability of cement based concrete plays an important role in the performance and service life of concrete constructions. A highly permeable concrete helps to place excessive water inside it (Bahia and Benson 2001). Concrete resembles a "hard sponge" that absorbs liquids like water and other aggressive substances. The strength of concrete is reduced by the influence of such substances. Therefore it is essential to produce concrete with maximum impermeability to damaging liquids.

Despite of the three basic ingredients which are cement, aggregates and water in conventional concrete, active mineral additives like fly ash (FA), blast furnace slag (BFS), rice husk ash (RHA) and nano silica (NS) particles have been incorporated to make high-strength and durable (low permeable) concrete (Neville 1995; Metha and Artcin 1990; Alves et al. 2004). In addition, maintaining a low water to binder ratio with adequate workability makes the design process more complicated (Parichatprecha and Nimityongskul 2009).

Conventionally, expert civil engineers could make HPC mix designs by using empirical results from earlier research plus their experience to obtain the required performance (Zain et al. 2005). However, existing results were often of limited value because some types of components and some properties have not been considered. Currently, concrete can 
be made with about 10 diverse components. The quantity of properties to be adjusted has also enlarged, so experimental methods are no longer adequate in concrete mix design (Yeh 1999). Unfortunately, standard and easy-to-use equations do not yet exist in design codes for accurately predicting the properties of HPC. Furthermore, with the abovementioned models, the assessment of the effect of each factor on the properties of concrete is approximately impossible (Akkurt et al. 2003; Oztas et al. 2006; Pala and Ozbay 2007; Caijun 2004; Zhao et al. 1998; Sirivivatnanon and Cao 1998; Chindaprasirt et al. 2007).

Currently, there has been a growing interest in a class of computing programs which known as artificial neural networks (ANNs) that function in a manner analogous to biological nervous systems. The neural network modeling (NNM) approach is very accurate and more direct than other conventional statistical methods, especially when modeling nonlinear multivariate interrelationships (Sobhani et al. 2010; Hagan et al. 1996; Rumellhert et al. 1986). Very recently, many researchers have used neural networks models for predicting various properties of concrete. The principal property of ANN in solving civil engineering problems are their learning ability directly from experiments. The other significant properties of ANN are their accurate or nearly accurate response to incomplete tasks, their withdrawal of information from noisy or poor data, and their creation of generalized results from the novel cases. The aforementioned potentials make ANN a very powerful tool for solving many civil engineering problems which deals with complex or an insufficient data (Ince 2004; Topçu and Sarıdemir 2008; Topçu and Sarıdemir 2007, 2008; Pala and Özbay 2007; Adhikary and Mutsuyoshi 2006).

The aim of this work is to create an ANN model to predict the influences of mix proportion parameters on the resistance of water absorption of ternary blended concrete incorporating NS and RHA which was has not been investigated to the present. To this end, data for developing the NNM were collected from our previous trials. The model was trained with 140 data of experimental results and then rests were used as only experimental input values for testing and verifying and values near to the experimental results were obtained.

\section{Experimental Map}

\subsection{Materials and Mixtures}

\subsubsection{Cement}

Ordinary Portland cement (OPC) obtained from Holcim Cement Manufacturing Company of Malaysia conforming to ASTM C150 standard was received and used. The chemical and physical properties of the cement are shown in Table 1.

\subsubsection{Rice Husk Ash}

The RHA was produced by controlled incineration by a local supplier. The as-received ash was sieved and the particles passing the finesses of $33 \mu \mathrm{m}$ were grinded using Los Angeles mill for 180 min respectively which yielded RHA samples having average particle size of $5 \mu \mathrm{m}$ (Naji Givi et al. 2010). The chemical composition and physical properties of RHA are given in Table 1. Also the particle size distribution curves of OPC and RHA with average particle size of $5 \mu \mathrm{m}$ are shown in Fig. 1.

\subsection{3 $\mathrm{SiO}_{2}$ Nanoparticles}

Two different $\mathrm{SiO}_{2}$ nano-particles with average diameters of 15 and $80 \mathrm{~nm}$ obtained from Nanostructured \& Amorphous Materials, Inc. of USA were received and used. The properties of the utilized nano-particles are presented in Table 2.

\subsubsection{Aggregates}

Locally available natural sand with particles smaller than $0.5 \mathrm{~mm}$, fineness modulus of 2.25 and specific gravity of $2.58 \mathrm{~g} / \mathrm{cm}^{3}$ was used as fine aggregate. Crushed basalt stored in the laboratory with maximum size of $15 \mathrm{~mm}$ and specific gravity of $2.96 \mathrm{~g} / \mathrm{cm}^{3}$ was used as coarse aggregate.

\subsubsection{Mixture Proportioning}

A total of five series of mixtures were prepared in the laboratory trials. $\mathrm{C} 01$ and $\mathrm{C} 02$ series mixtures were prepared as control specimens and cured in water and saturated lime water, respectively. The control mixtures were made of natural aggregates, cement and water. $\mathrm{U}(\mathrm{W}$ and $\mathrm{LW}$ ) series concrete were made by partial replacement of cement with RHA average particle size of $5 \mu \mathrm{m}$ and cured in water and saturated lime water, respectively. Finally $\mathrm{CN}-\mathrm{RHA}$ and FN-RHA series were prepared by different amounts of $5 \mu \mathrm{m}$ RHA incorporating with 80 and $15 \mathrm{~nm}$ of $\mathrm{SiO}_{2}$ particles, respectively. The curing medium $(\mathrm{CM})$ for these series was saturate lime water.

The water to binder ratio for all mixtures was set at 0.40 . The aggregates for the mixtures consisted of a combination of crushed basalt and fine sand, with $30 \mathrm{wt} . \%$ of sand. The binder content of all mixtures was $450 \mathrm{~kg} / \mathrm{m}^{3}$. The proportions of the mixtures are presented in Table 3.

\subsection{Preparation of Test Specimens}

The mentioned mixtures were mixed in dry condition for 2 min followed by another $3 \mathrm{~min}$ after adding the water. Cubes of $100 \mathrm{~mm}$ edge were casted and compacted in two layers on a vibrating table, where each layer was vibrated for $10 \mathrm{~s}$. The moulds were covered with polyethylene sheets and moistened for $24 \mathrm{~h}$. Then the specimens were demoulded and cured in water or saturated limewater at a temperature of $20{ }^{\circ} \mathrm{C}$ prior to test days. The percentage, velocity and coefficient of water absorption test of the concrete samples were determined at 7,28 and 90 days. The reported results are the average of three trials.

\subsection{Percentage of Water Absorption of Nano Silica-RHA Particles Blended Concrete}

Percentage of water absorption is an evaluation of the pore volume or porosity of concrete after hardening, which is occupied by water in saturated state. Water absorption values of NS-RHA particles blended concrete samples were 
Table 1 Chemical and physical properties of Portland cement and RHA (wt.\%).

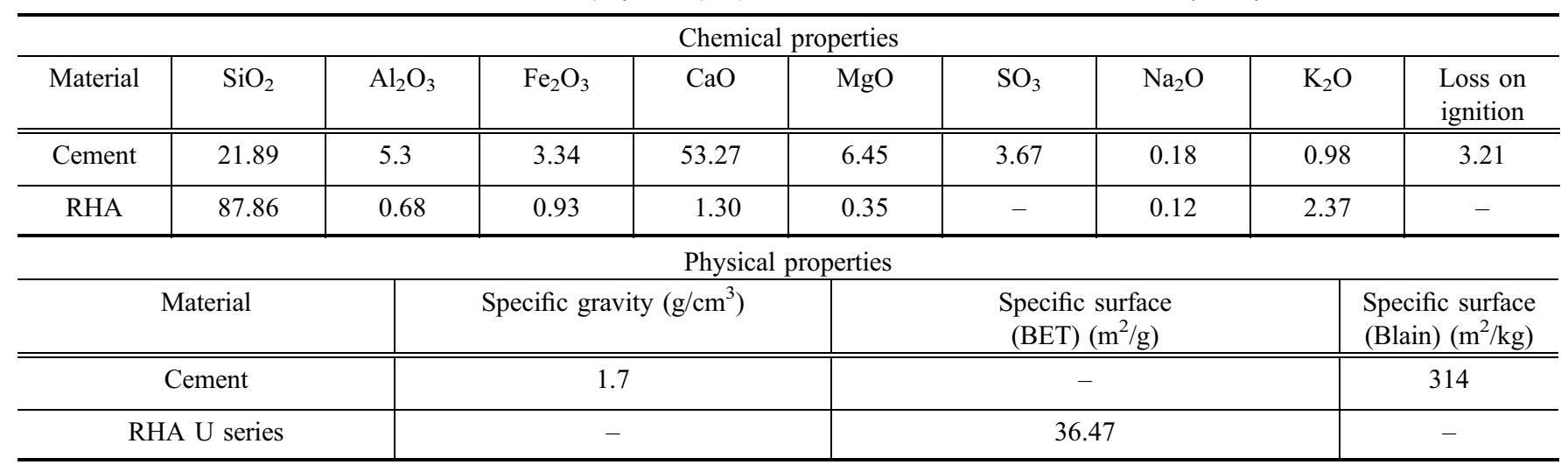

RHA rice husk ash, $U$ series ultra fine RHA blended concrete.

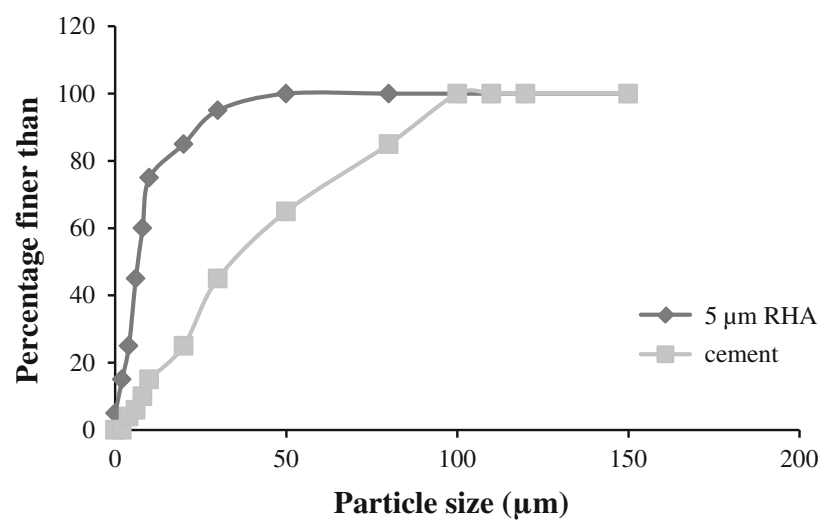

Fig. 1 The particle size distribution curves of OPC and RHA.

measured as per ASTM C 642 at 7, 28 and 90 days of moisture curing.

\subsection{Velocity of Water Absorption of NS-RHA Particles Blended Concrete}

Speed of water absorption is a measure of the capillary forces exerted by the pore structure causing fluids to be drawn into the body of the material (Martys and Ferraris 1997). In this experiment, the speed of water absorption by concrete cubes were considered by measuring the increase in the mass of samples due to water absorption at certain times when only one surface of the specimen is exposed to water. Concrete samples were dried in an oven at $50{ }^{\circ} \mathrm{C}$ for three days and then cooled in a sealed container at $23{ }^{\circ} \mathrm{C}$ for fifteen days as per ASTM C1585 at 7, 28 and 90 days of moist curing (Ransinchung et al. 2009). The sides of the concrete samples were covered with epoxy resin in order to allow the flow of water in one direction. The end of the samples were sealed with tightly attached plastic sheet and protected in position by an elastic band. The initial mass of the samples were taken after which they were kept partly immersed to a depth of $5 \mathrm{~mm}$ in water as shown in Fig. 2.
The readings were started with the initial mass of the sample at selected times after first contact with water (typically 1, 5, 10, 20, 30, 60, 110 and $120 \mathrm{~min}$ ) (Ganesan et al. 2008), the samples were removed, excess water was blotted off using paper towel and then weighed. Then they were replaced again in water for the chosen time period. The gain in mass $\left(\Delta m, \mathrm{~kg} / \mathrm{s}^{1 / 2}\right)$ at time $\mathrm{t}(\mathrm{s})$, exposed area of the specimen $\left(a, \mathrm{~m}^{2}\right)$, and density of water $\left(d, \mathrm{~kg} / \mathrm{m}^{3}\right)$, were used to obtain the rate of water absorption $\left(I, \mathrm{~m} / \mathrm{s}^{1 / 2}\right)$ as per the equation (Ransinchung et al. 2009):

$$
I=\frac{\Delta m}{(a \times d)} .
$$

\subsection{Coefficient of Water Absorption}

Coefficient of water absorption is considered as a measure of permeability of water (Powers 1968). This was measured by determining the rate of water uptake by dry concrete in a period of $1 \mathrm{~h}$ (Ganesan et al. 2008). The concrete samples were dried at $110{ }^{\circ} \mathrm{C}$ in an oven for one week until they reached to constant weight and then were cooled in a sealed container for 1 day. The sides of the samples were covered with epoxy resin, and were placed partly immersed in water to a depth of $5 \mathrm{~mm}$ at one end, and at the other end a tightly attached plastic was secured in position by an elastic band as shown in Fig. 2 (Ransinchung et al. 2009). The amount of water absorbed during the first 60 min was calculated for concrete samples after 7, 28 and 90 days of moisture curing using the formula (Ganesan et al. 2008):

$$
K a=\left(\frac{Q}{A}\right)^{2} \cdot \frac{1}{t},
$$

where $K a$ is the coefficient of water absorption $\left(\mathrm{m}^{2} / \mathrm{s}\right), Q$ is the quantity of water absorbed $\left(\mathrm{m}^{3}\right)$ by the dried samples in $3,600 \mathrm{~s}$ and $A$ is the surface area $\left(\mathrm{m}^{2}\right)$ of concrete samples through which water penetrates.

Table 2 The properties of NS.

\begin{tabular}{c|c|c|c}
\hline Diameter $(\mathrm{nm})$ & Surface volume ratio $\left(\mathrm{m}^{2} / \mathrm{g}\right)$ & Density $\left(\mathrm{g} / \mathrm{cm}^{3}\right)$ & Purity $(\%)$ \\
\hline \hline $15 \pm 3$ & $160 \pm 12$ & $<0.14$ & $>99.9$ \\
\hline $80 \pm 5$ & $560 \pm 32$ & $<0.14$ & $>99.9$ \\
\hline
\end{tabular}


Table 3 The proportions of the mixtures.

\begin{tabular}{|c|c|c|c|c|c|}
\hline Sample number & Sample designations & Cement $\left(\mathrm{kg} / \mathrm{m}^{3}\right)$ & $\mathrm{RHA}^{\mathrm{a}}\left(\mathrm{kg} / \mathrm{m}^{3}\right)$ & $\begin{array}{c}15 \mathrm{~nm} \text { nanoparticle } \\
\left(\mathrm{kg} / \mathrm{m}^{3}\right)\end{array}$ & $\begin{array}{c}80 \mathrm{~nm} \text { nano particle } \\
\left(\mathrm{kg} / \mathrm{m}^{3}\right)\end{array}$ \\
\hline 1,2 & $\mathrm{C}^{\mathrm{a}} 1,2$ & 450 & 0 & 0 & 0 \\
\hline 3,4 & $\mathrm{U}^{\mathrm{b}} 1$ & 427.5 & 22.5 & 0 & 0 \\
\hline 5,6 & $\mathrm{U} 2$ & 405 & 45 & 0 & 0 \\
\hline 7,8 & U3 & 382.5 & 67.5 & 0 & 0 \\
\hline 9,10 & U4 & 360 & 90 & 0 & 0 \\
\hline 11,12 & $\mathrm{FN} 1^{\mathrm{c}}$ & 447.75 & 0 & 2.25 & 0 \\
\hline 13,14 & FN2 & 445.5 & 0 & 4.5 & 0 \\
\hline 15,16 & FN3 & 443.25 & 0 & 6.75 & 0 \\
\hline 17,18 & FN4 & 441 & 0 & 9 & 0 \\
\hline 19,20 & $\mathrm{CN} 1^{\mathrm{d}}$ & 447.75 & 0 & 0 & 2.25 \\
\hline 21,22 & $\mathrm{CN} 2$ & 445.5 & 0 & 0 & 4.5 \\
\hline 23,24 & $\mathrm{CN} 3$ & 443.25 & 0 & 0 & 6.75 \\
\hline 25,26 & $\mathrm{CN} 4$ & 441 & 0 & 0 & 9 \\
\hline 27 & FN1-RHA 5 & 425.25 & 22.5 & 2.25 & 0 \\
\hline 28 & FN2-RHA5 & 423 & 22.5 & 4.5 & 0 \\
\hline 29 & FN3-RHA5 & 420.75 & 22.5 & 6.75 & 0 \\
\hline 30 & FN4-RHA5 & 418.5 & 22.5 & 9 & 0 \\
\hline 31 & FN1-RHA10 & 402.75 & 45 & 2.25 & 0 \\
\hline 32 & FN2-RHA10 & 400.5 & 45 & 4.5 & 0 \\
\hline 33 & FN3-RHA10 & 398.25 & 45 & 6.75 & 0 \\
\hline 34 & FN4-RHA10 & 396 & 45 & 9 & 0 \\
\hline 35 & FN1-RHA15 & 380.25 & 67.5 & 2.25 & 0 \\
\hline 36 & FN2-RHA15 & 378 & 67.5 & 4.5 & 0 \\
\hline 37 & FN3-RHA15 & 375.75 & 67.5 & 6.75 & 0 \\
\hline 38 & FN4-RHA15 & 373.5 & 67.5 & 9 & 0 \\
\hline 39 & FN1-RHA20 & 357.75 & 90 & 2.25 & 0 \\
\hline 40 & FN2-RHA20 & 355.5 & 90 & 4.5 & 0 \\
\hline 41 & FN3-RHA20 & 353.25 & 90 & 6.75 & 0 \\
\hline 42 & FN4-RHA20 & 351 & 90 & 9 & 0 \\
\hline 43 & CN1-RHA ${ }^{\mathrm{f}_{5}}$ & 425.25 & 22.5 & 0 & 2.25 \\
\hline 44 & CN2-RHA5 & 423 & 22.5 & 0 & 4.5 \\
\hline 45 & CN3-RHA5 & 420.75 & 22.5 & 0 & 6.75 \\
\hline 46 & CN4-RHA5 & 418.5 & 22.5 & 0 & 9 \\
\hline 47 & CN1-RHA10 & 402.75 & 45 & 0 & 2.25 \\
\hline 48 & CN2-RHA10 & 400.5 & 45 & 0 & 4.5 \\
\hline 49 & CN3-RHA10 & 398.25 & 45 & 0 & 6.75 \\
\hline 50 & CN4-RHA10 & 396 & 45 & 0 & 9 \\
\hline 51 & CN1-RHA15 & 380.25 & 67.5 & 0 & 2.25 \\
\hline 52 & CN2-RHA15 & 378 & 67.5 & 0 & 4.5 \\
\hline
\end{tabular}


Table 3 continued

\begin{tabular}{c|c|c|c|c|c}
\hline Sample number & Sample designations & Cement $\left(\mathrm{kg} / \mathrm{m}^{3}\right)$ & $\mathrm{RHA}^{\mathrm{a}}\left(\mathrm{kg} / \mathrm{m}^{3}\right)$ & $\begin{array}{c}15 \mathrm{~nm} \text { nanoparticle } \\
\left(\mathrm{kg} / \mathrm{m}^{3}\right)\end{array}$ & $\begin{array}{c}80 \mathrm{~nm} \text { nano particle } \\
\left(\mathrm{kg} / \mathrm{m}^{3}\right)\end{array}$ \\
\hline \hline 53 & CN3-RHA15 & 375.75 & 67.5 & 0 & 6.75 \\
\hline 54 & CN4-RHA15 & 373.5 & 67.5 & 0 & 9 \\
\hline 55 & CN1-RHA20 & 357.75 & 90 & 0 & 2.25 \\
\hline 56 & CN2-RHA20 & 355.5 & 90 & 0 & 4.5 \\
\hline 57 & CN3-RHA20 & 353.25 & 90 & 0 & 6.75 \\
\hline 58 & CN4-RHA20 & 351 & 90 & & 9 \\
\hline
\end{tabular}

\footnotetext{
${ }^{a}$ Control concrete.

${ }^{\mathrm{b}}$ Concrete samples containing $5 \mu \mathrm{m}$ RHA particles.

${ }^{c}$ Concrete samples containing $15 \mathrm{~nm} \mathrm{SiO}_{2}$ particles.

${ }^{\mathrm{d}}$ Concrete samples containing $80 \mathrm{~nm} \mathrm{SiO} 2$ particles.

e Concrete samples containing $15 \mathrm{~nm} \mathrm{SiO}_{2}$ particles together with $5 \mu \mathrm{m}$ RHA particles.

${ }^{\mathrm{f}}$ Concrete samples containing $80 \mathrm{~nm} \mathrm{SiO}_{2}$ particles together with $5 \mu \mathrm{m}$ RHA particles.
}

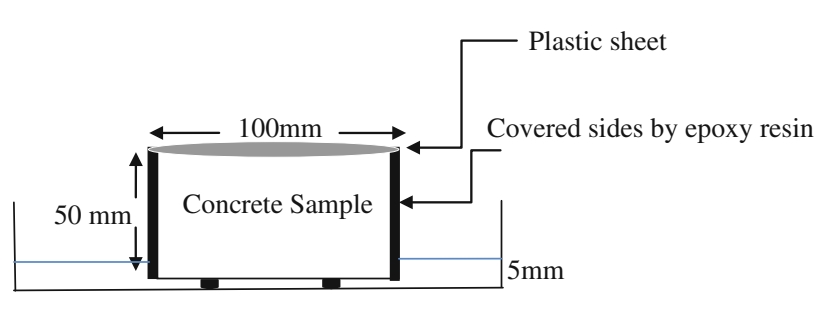

Fig. 2 Velocity and coefficient of water absorption test procedure.

For development of an ANN model, a total of 38 different $\mathrm{C} 0, \mathrm{U}, \mathrm{FN}-\mathrm{RHA}$ and CN-RHA were selected. Each of these mixes differs by material contents and $\mathrm{CM}$ from one another. Then, a total of 342 cubic samples were collected.

\section{Experimental Results and Discussion}

\subsection{Percentage of Water Absorption}

The results of saturated water absorption at 7, 28 and 90 days of moist curing are shown in Table 4 for C01, C02, U, CN-RHA and FN-RHA series concrete, respectively. The percentage of water absorption of concrete samples immersed in water or saturated lime water was decreased with increasing the age of moist curing from 7 to 90 days for all five series during the hardening process of the concrete. By comparison the percentage of water absorption in FN series concrete and $U$ series concrete, one could observe that the water permeability in FN series only at 28 days of curing is lower than that of $U$ series concrete. This is due to the differences between the nature of the NS and RHA particles. $\mathrm{SiO}_{2}$ nanoparticles which were finely dispersed in the cement paste formed more nucleation sites with much higher specific surface resulted in rapid formation of $\mathrm{C}-\mathrm{S}-\mathrm{H}$ gel. Since formation of $\mathrm{C}-$ $\mathrm{S}-\mathrm{H}$ gel requires water to complete the reaction, the percentage of water absorption in $\mathrm{FN}$ series concrete was more than those of $\mathrm{U}$ series. After 28 days of curing, since formation of $\mathrm{C}-\mathrm{S}-\mathrm{H}$ gel was accelerated in $\mathrm{U}$ series in presence of RHA, the percentage of water absorption in $\mathrm{U}$ series was more than that of FN series. Finally at 90 days of curing, more $\mathrm{C}-\mathrm{S}-\mathrm{H}$ gel was formed in presence of RHA thus the percentage of water absorption in $\mathrm{U}$ series (up to $10 \mathrm{wt} \%$ replacement of concrete by RHA) was more than those of FN series. Since curing in water results in finishing $\mathrm{Ca}(\mathrm{OH})_{2}$ (Naji Givi et al. 2010a; b) and no more $\mathrm{C}-\mathrm{S}-\mathrm{H}$ gel was formed, the increase in water absorption which is related to the increase in the amount of RHA could be resulted from the reduced amount of OPC.

By comparison the percentage of water absorption of FNRHA series concrete (Table 4) with those of $U$ and FN series, it is seen that the percentage of water absorption in FN-RHA series concrete after 7 and 28 days of curing is more than those of the other series ( $\mathrm{U}$ and FN series). This may due to the sequence of $\mathrm{C}-\mathrm{S}-\mathrm{H}$ gel formation which was accelerated at 7 days as a result of $\mathrm{SiO}_{2}$ nanoparticles reaction and at 28 days because of RHA particles reaction. After 90 days of curing, the percentage of water absorption of ternary blended concrete was considerably lower than those of $\mathrm{U}$ and FN series. That was due to more $\mathrm{C}-\mathrm{S}-\mathrm{H}$ gel formation which blocks water diffusion paths and filling of micro- and nano-voids.

Similarly, by comparison the percentage of water absorption of CN-RHA series concrete (Table 4) with those of $U$ and $\mathrm{CN}$ series, it was seen that the percentage of water absorption in CN-RHA series was more than those of $U$ and $\mathrm{CN}$ series. This condition after 90 days of curing was inverse and similar to FN-RHA series; the percentage of water absorption was much lower than those of $\mathrm{U}$ and $\mathrm{CN}$ series. Also, this value for CN-RHA series was better than FN-RHA series as a result of more $\mathrm{C}-\mathrm{S}-\mathrm{H}$ gel formation at 90 days of moist curing. 
Table 4 Experimental results of percentage, velocity and coefficient of water absorption.

\begin{tabular}{|c|c|c|c|c|c|c|c|c|c|c|}
\hline \multirow{2}{*}{$\begin{array}{l}\text { Sample } \\
\text { number }\end{array}$} & \multirow{2}{*}{\begin{tabular}{c|} 
Sample \\
designations
\end{tabular}} & \multicolumn{3}{|c|}{ Percentage of water absorption (\%) } & \multicolumn{3}{|c|}{ Velocity of water absorption $\left(\mathrm{m} / \mathrm{s}^{1 / 2}\right)$} & \multicolumn{3}{|c|}{ Coefficient of water absorption $\left(\mathrm{m}^{2} / \mathrm{s}\right)$} \\
\hline & & 7 & 28 & 90 & 7 & 28 & 90 & 7 & 28 & 90 \\
\hline 1 & $\mathrm{C} 01^{\mathrm{a}}$ & 7.47 & 5.60 & 4.80 & 13.22 & 12.34 & 10.14 & 9.02 & 2.86 & 1.35 \\
\hline 2 & $\mathrm{C} 02$ & 8.32 & 5.71 & 4.92 & 13.26 & 12.56 & 10.18 & 9.06 & 2.98 & 1.40 \\
\hline 3 & $\mathrm{U} 1^{\mathrm{b}}(\mathrm{W})$ & 6.90 & 5.22 & 3.98 & 12.64 & 11.38 & 6.89 & 8.56 & 2.47 & 1.03 \\
\hline 4 & $\mathrm{U} 1^{\mathrm{b}}(\mathrm{LW})$ & 6.94 & 5.54 & 3.84 & 12.65 & 11.41 & 6.85 & 8.61 & 2.49 & 1.02 \\
\hline 5 & $\mathrm{U} 2(\mathrm{~W})$ & 6.67 & 5.11 & 3.51 & 10.72 & 8.64 & 5.14 & 7.30 & 1.97 & 0.89 \\
\hline 6 & $\mathrm{U} 2$ (LW) & 6.73 & 5.42 & 3.36 & 10.80 & 8.67 & 5.09 & 7.33 & 2.00 & 0.88 \\
\hline 7 & U3 (W) & 6.94 & 5.28 & 4.01 & 12.60 & 11.70 & 8.32 & 8.67 & 2.55 & 1.12 \\
\hline 8 & U3 (LW) & 6.54 & 5.33 & 3.14 & 10.78 & 8.66 & 5.05 & 7.29 & 1.97 & 0.85 \\
\hline 9 & U4 (W) & 7.10 & 5.41 & 4.14 & 12.86 & 11.73 & 9.16 & 8.83 & 2.57 & 1.20 \\
\hline 10 & U4 (LW) & 6.32 & 5.19 & 3.02 & 10.69 & 8.62 & 4.99 & 7.26 & 1.96 & 0.84 \\
\hline 11 & $\mathrm{FN}^{\mathrm{c}} 1(\mathrm{~W})$ & 7.15 & 4.82 & 4.12 & 12.83 & 7.51 & 7.09 & 7.82 & 1.53 & 1.30 \\
\hline 12 & $\mathrm{FN}^{\mathrm{c}} 1(\mathrm{LW})$ & 7.20 & 4.71 & 4.00 & 12.85 & 7.53 & 7.00 & 7.85 & 1.52 & 1.28 \\
\hline 13 & FN2 (W) & 7.23 & 4.73 & 4.01 & 12.95 & 7.25 & 6.78 & 7.96 & 1.48 & 1.18 \\
\hline 14 & FN2 (LW) & 7.28 & 4.56 & 3.86 & 13.00 & 7.23 & 6.67 & 7.98 & 1.46 & 1.12 \\
\hline 15 & FN3 (W) & 7.31 & 4.60 & 3.92 & 13.07 & 6.99 & 6.52 & 8.15 & 1.44 & 1.07 \\
\hline 16 & FN3 (LW) & 7.42 & 4.39 & 3.71 & 13.10 & 6.95 & 6.48 & 8.20 & 1.40 & 1.04 \\
\hline 17 & FN4 (W) & 7.42 & 4.41 & 3.78 & 13.18 & 6.73 & 6.35 & 8.32 & 1.39 & 0.95 \\
\hline 18 & FN4 (LW) & 7.56 & 4.22 & 3.54 & 13.21 & 6.69 & 6.31 & 8.37 & 1.36 & 0.92 \\
\hline 19 & $\mathrm{CN}^{\mathrm{d}} 1(\mathrm{~W})$ & 7.02 & 5.00 & 4.05 & 12.67 & 8.01 & 6.81 & 7.69 & 1.56 & 1.25 \\
\hline 20 & $\mathrm{CN}^{\mathrm{d}} 1(\mathrm{LW})$ & 7.10 & 5.02 & 3.91 & 12.73 & 8.07 & 6.78 & 7.74 & 1.59 & 1.23 \\
\hline 21 & CN2 (W) & 7.10 & 5.08 & 3.94 & 12.82 & 8.23 & 6.65 & 7.83 & 1.67 & 1.13 \\
\hline 22 & CN2 (LW) & 7.16 & 5.12 & 3.80 & 12.87 & 8.27 & 6.63 & 7.85 & 1.69 & 1.09 \\
\hline 23 & CN3 (W) & 7.21 & 5.17 & 3.87 & 12.91 & 8.42 & 6.42 & 7.99 & 1.79 & 1.01 \\
\hline 24 & CN3 (LW) & 7.23 & 5.23 & 3.68 & 12.94 & 8.47 & 6.36 & 8.03 & 1.82 & 0.98 \\
\hline 25 & CN4 (W) & 7.29 & 5.32 & 3.71 & 13.06 & 8.61 & 6.21 & 8.18 & 1.88 & 0.88 \\
\hline 26 & CN4 (LW) & 7.34 & 5.35 & 3.51 & 13.09 & 8.65 & 6.18 & 8.21 & 1.89 & 0.85 \\
\hline 27 & FN1-RHA ${ }^{\mathrm{e}} 5$ & 7.22 & 5.00 & 3.32 & 13.48 & 7.93 & 4.71 & 9.18 & 1.49 & 0.83 \\
\hline 28 & FN2-RHA5 & 7.29 & 5.02 & 2.96 & 13.68 & 8.03 & 4.57 & 9.27 & 1.53 & 0.80 \\
\hline 29 & FN3-RHA5 & 7.46 & 5.07 & 2.71 & 13.86 & 8.08 & 4.46 & 9.34 & 1.58 & 0.72 \\
\hline 30 & FN4-RHA5 & 7.61 & 5.12 & 2.54 & 13.90 & 8.15 & 4.34 & 9.58 & 1.64 & 0.67 \\
\hline 31 & FN1-RHA10 & 7.24 & 5.03 & 3.30 & 13.50 & 7.96 & 4.69 & 9.21 & 1.56 & 0.81 \\
\hline 32 & FN2-RHA10 & 7.32 & 5.07 & 2.90 & 13.72 & 8.09 & 4.54 & 9.32 & 1.59 & 0.74 \\
\hline 33 & FN3-RHA10 & 7.51 & 5.13 & 2.62 & 13.95 & 8.16 & 4.38 & 9.43 & 1.65 & 0.63 \\
\hline 34 & FN4-RHA10 & 7.64 & 5.21 & 2.49 & 14.15 & 8.27 & 4.22 & 9.71 & 1.73 & 0.51 \\
\hline 35 & FN1-RHA15 & 7.43 & 5.14 & 3.11 & 13.71 & 8.11 & 4.51 & 9.38 & 1.59 & 0.69 \\
\hline 36 & FN2-RHA15 & 7.61 & 5.19 & 2.81 & 13.98 & 8.23 & 4.46 & 9.54 & 1.62 & 0.61 \\
\hline 37 & FN3-RHA15 & 7.82 & 5.25 & 2.50 & 14.18 & 8.34 & 4.28 & 9.68 & 1.69 & 0.54 \\
\hline 38 & FN4-RHA15 & 7.91 & 5.39 & 2.38 & 14.37 & 8.41 & 4.12 & 9.87 & 1.74 & 0.48 \\
\hline 39 & FN1-RHA20 & 7.62 & 5.19 & 2.99 & 13.86 & 8.21 & 4.38 & 9.49 & 1.61 & 0.63 \\
\hline 40 & FN2-RHA20 & 7.81 & 5.23 & 2.71 & 14.05 & 8.36 & 4.26 & 9.68 & 1.72 & 0.58 \\
\hline 41 & FN3-RHA20 & 7.95 & 5.42 & 2.42 & 14.26 & 8.44 & 4.11 & 9.79 & 1.79 & 0.50 \\
\hline
\end{tabular}


Table 4 continued

\begin{tabular}{|c|c|c|c|c|c|c|c|c|c|c|}
\hline \multirow{2}{*}{$\begin{array}{l}\text { Sample } \\
\text { number }\end{array}$} & \multirow{2}{*}{$\begin{array}{c}\text { Sample } \\
\text { designations }\end{array}$} & \multicolumn{3}{|c|}{ Percentage of water absorption (\%) } & \multicolumn{3}{|c|}{ Velocity of water absorption $\left(\mathrm{m} / \mathrm{s}^{1 / 2}\right)$} & \multicolumn{3}{|c|}{ Coefficient of water absorption $\left(\mathrm{m}^{2} / \mathrm{s}\right)$} \\
\hline & & 7 & 28 & 90 & 7 & 28 & 90 & 7 & 28 & 90 \\
\hline 42 & FN4-RHA20 & 8.01 & 5.51 & 2.21 & 14.51 & 8.56 & 4.01 & 9.96 & 1.91 & 0.43 \\
\hline 43 & CN1-RHA ${ }^{\mathrm{f}} 5$ & 7.07 & 5.03 & 3.12 & 12.88 & 8.26 & 4.26 & 8.83 & 1.69 & 0.77 \\
\hline 44 & CN2-RHA5 & 7.16 & 5.08 & 2.80 & 12.92 & 8.31 & 4.01 & 8.92 & 1.72 & 0.71 \\
\hline 45 & CN3-RHA5 & 7.20 & 5.19 & 2.57 & 13.04 & 8.42 & 3.89 & 8.99 & 1.78 & 0.69 \\
\hline 46 & CN4-RHA5 & 7.28 & 5.23 & 2.46 & 13.21 & 8.58 & 3.72 & 9.11 & 1.84 & 0.60 \\
\hline 47 & $\begin{array}{l}\text { CN1- } \\
\text { RHA10 }\end{array}$ & 7.10 & 5.05 & 3.00 & 12.91 & 8.32 & 4.12 & 8.91 & 1.73 & 0.70 \\
\hline 48 & $\begin{array}{l}\text { CN2- } \\
\text { RHA10 }\end{array}$ & 7.19 & 5.14 & 2.61 & 13.08 & 8.45 & 3.89 & 9.05 & 1.82 & 0.65 \\
\hline 49 & $\begin{array}{l}\text { CN3- } \\
\text { RHA10 }\end{array}$ & 7.29 & 5.26 & 2.42 & 13.24 & 8.59 & 3.76 & 9.17 & 1.91 & 0.61 \\
\hline 50 & $\begin{array}{l}\text { CN4- } \\
\text { RHA10 }\end{array}$ & 7.47 & 5.38 & 2.24 & 13.45 & 8.73 & 3.52 & 9.26 & 2.01 & 0.54 \\
\hline 51 & $\begin{array}{l}\text { CN1- } \\
\text { RHA15 }\end{array}$ & 7.22 & 5.22 & 2.82 & 13.14 & 8.46 & 4.00 & 9.01 & 1.84 & 0.61 \\
\hline 52 & $\begin{array}{l}\text { CN2- } \\
\text { RHA15 }\end{array}$ & 7.31 & 5.34 & 2.61 & 13.29 & 8.61 & 3.72 & 9.15 & 1.96 & 0.53 \\
\hline 53 & $\begin{array}{l}\text { CN3- } \\
\text { RHA15 }\end{array}$ & 7.39 & 5.47 & 2.40 & 13.38 & 8.75 & 3.61 & 9.32 & 2.09 & 0.48 \\
\hline 54 & $\begin{array}{l}\text { CN4- } \\
\text { RHA15 }\end{array}$ & 7.51 & 5.58 & 2.22 & 13.54 & 8.91 & 3.41 & 9.44 & 2.21 & 0.42 \\
\hline 55 & $\begin{array}{l}\text { CN1- } \\
\text { RHA20 }\end{array}$ & 7.34 & 5.31 & 2.68 & 13.27 & 8.58 & 3.82 & 9.13 & 1.96 & 0.54 \\
\hline 56 & $\begin{array}{l}\text { CN2- } \\
\text { RHA20 }\end{array}$ & 7.45 & 5.49 & 2.50 & 13.42 & 8.73 & 3.61 & 9.32 & 2.11 & 0.46 \\
\hline 57 & $\begin{array}{l}\text { CN3- } \\
\text { RHA20 }\end{array}$ & 7.52 & 5.59 & 2.29 & 13.59 & 8.88 & 3.45 & 9.48 & 2.23 & 0.39 \\
\hline 58 & $\begin{array}{l}\text { CN4- } \\
\text { RHA20 }\end{array}$ & 7.61 & 5.80 & 2.08 & 13.71 & 9.04 & 3.29 & 9.66 & 2.35 & 0.31 \\
\hline
\end{tabular}

a Control concrete.

${ }^{\mathrm{b}}$ Concrete samples containing $5 \mu$ RHA particles.

${ }^{\mathrm{c}}$ Concrete samples containing $15 \mathrm{~nm} \mathrm{SiO}_{2}$ particles.

${ }^{\text {d }}$ Concrete samples containing $80 \mathrm{~nm} \mathrm{SiO} 2$ particles.

e Concrete samples containing $15 \mathrm{~nm} \mathrm{SiO}_{2}$ particles together with $5 \mu$ RHA particles.

${ }^{\mathrm{f}}$ Concrete samples containing $80 \mathrm{~nm} \mathrm{SiO} \mathrm{S}_{2}$ particles together with $5 \mu$ RHA particles.

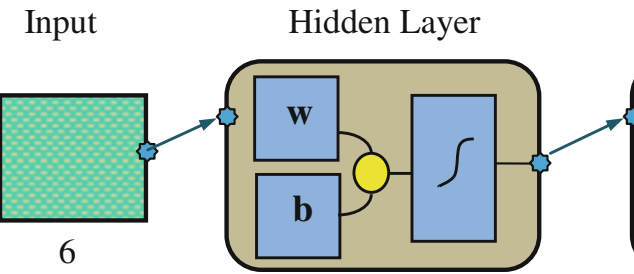

20
Output Layer Output

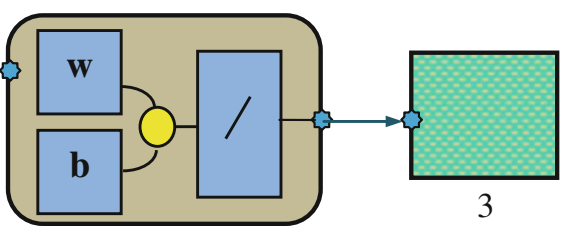

3

Fig. 3 Schematic of a fully connected, two-layer feed-forward network. $W$ and $b$ denote weights and biases, respectively.

\subsection{Velocity of Water Absorption}

The velocity of water absorption of CN-RHA and FNRHA series concrete are listed in Table 4. The velocity of water absorption also obeys the percentage of water absorption and in both FN-RHA and CN-RHA series was better than those of $\mathrm{U}, \mathrm{FN}$ and $\mathrm{CN}$ series. Since more $\mathrm{C}-\mathrm{S}-$ 
$\mathrm{H}$ gel was formed in FN-RHA and CN-RHA series, the water diffusion paths are blocked together with filler effects of $\mathrm{SiO}_{2}$ and RHA particles would result in reduced velocity of water absorption.

It is well known that mineral admixtures with fine particles can improve the filler effect and also the high pozzolanic action of fine particles increases substantially the quantity of $\mathrm{C}-\mathrm{S}-\mathrm{H}$ gel. If this phenomenon joins with low water cement ratio, it can improve the microstructure in the interfacial transition zones and thus the value of $\mathrm{C}-\mathrm{S}-\mathrm{H}$ gel, then the water permeability can be considerably increased.

All these events result in more homogeneous and stronger interfacial transition zones and reduction of their thickness, with less potential of micro cracks and uniform particle distribution which lead to the grain refinement of hydrated cement paste in the interfacial transition zone (Monteiro and Mehta 1986; Prabir et al. 2001). Hence, admixing of RHA and $\mathrm{SiO}_{2}$ nanoparticles to conventional concrete leads to physically and chemically rearrangement and improvement of the concrete microstructures. The speed of water absorption is very important to predict the service life of concrete as a structural material and to improve its performance (Martys and Ferraris 1997). Micro filler materials with fine particles can fill both the interfaces and the bulk

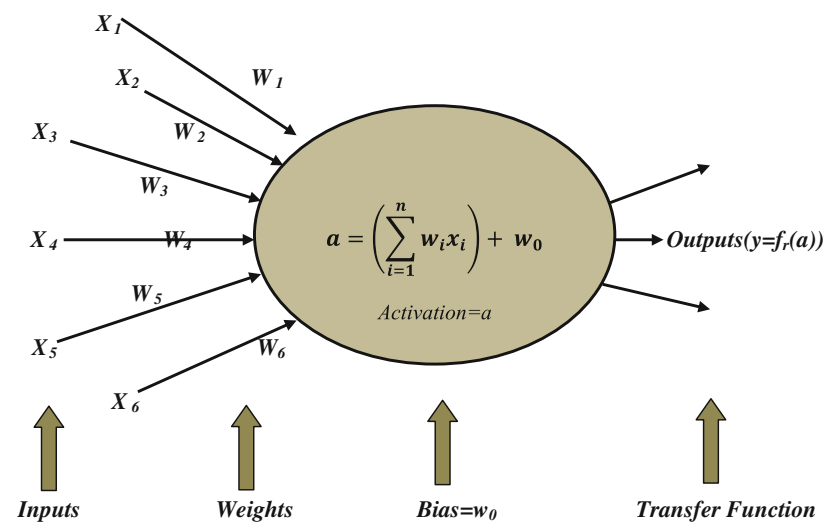

Fig. 4 Schematic illustration of a neuron. paste and develop discontinuous and tortuous pore in concrete structure causing reduction in the rate of water absorption (Tasdemir 2003; Wee et al. 2000). Micro and macro pores present in the concrete can be completely filled up by fine particles (Ganesan et al. 2008). The connectivity of pore system is characterized by the degree of water in filled voids in the concrete mix and the hydration products of concrete after hardening. Capillary pores are known as those voids which were originally filled with mixing water in the range of 3.2-3,000 $\mathrm{nm}$ diameter (Philleo 1986). These capillary pores can become unconnected under moist curing situation after about 3 days for concrete having w/c of 0.4 (Powers et al. 1959). C-NS-RHA ternary blended concrete shows a continued decrease of pore size and its continuity by increasing the curing time than OPC concretes.

\subsection{Coefficient of Water Absorption}

The coefficients of water absorption of NS-RHA particles blended concrete samples for CN-RHA and FN-RHA series concrete are also listed in Table 4 . The obtained results are similar to the manner that percentage and velocity of water absorption obey. Thus, no more justifications are presented here.

\section{Neural Network Modeling}

\subsection{Model Description}

The ANN trained in this study was a fully connected, twolayer feed-forward network with sigmoid hidden neurons and three outputs neurons. It could fit multi-dimensional mapping problems arbitrarily well, given consistent data and enough neurons in its hidden layer as shown in Fig. 3. The input layer consists of 6 input nodes and the output layer consists of 3 output nodes. Also the hidden layer has 6 nodes, in each node; weighted inputs are processed by a transfer function as shown in Fig. 4 (Hornik et al. 1994).

The network has been trained with Levenberg-Marquardt Backpropagation (LMBP) algorithm. ANNs are computing

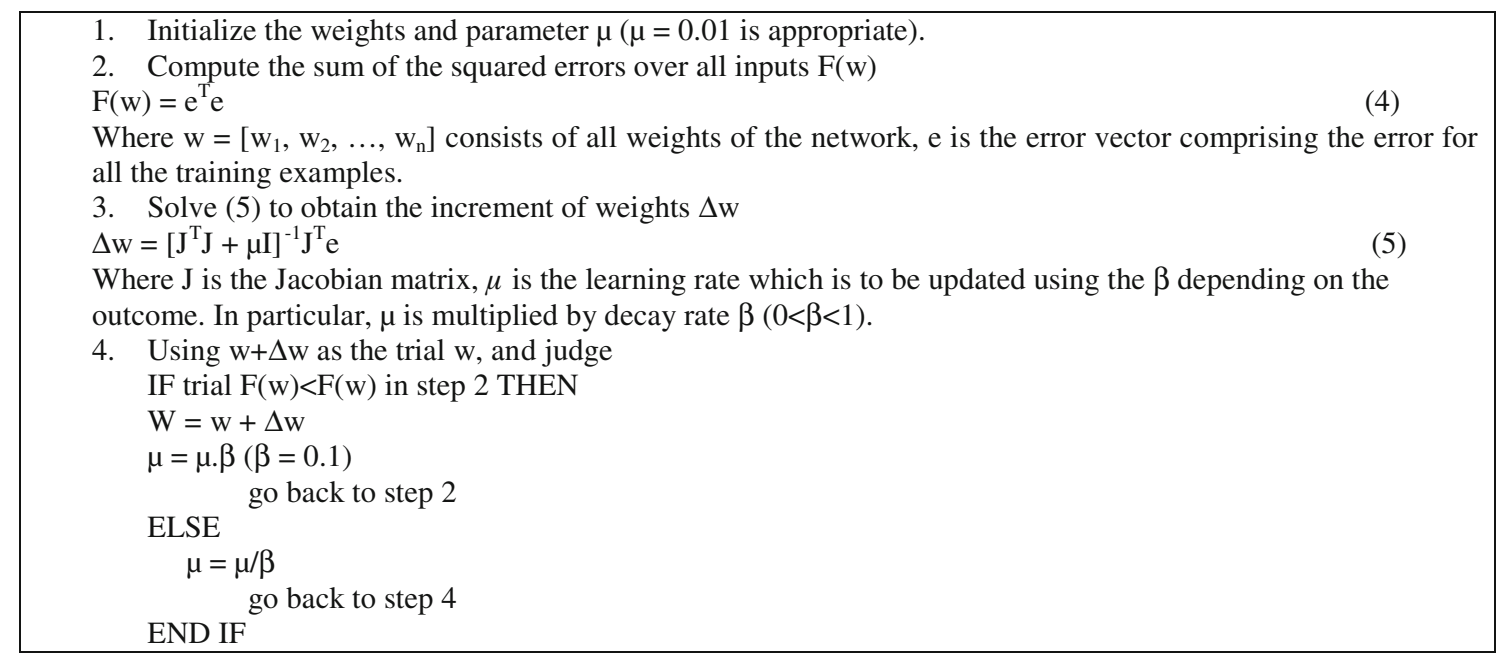

Fig. 5 Pseudo-code for LMBP algorithm. 
systems that simulate the biological neural systems of human brain. Conceptually, a neural networks model consists of a set of computational units and a set of one-way data connection joining units or weights as shown in Fig. 4. Units that receive no input from others are called input nodes, while those with no outgoing links are called output nodes. All other intermediate units are called hidden nodes.

Traditionally, the learning process is used to determine proper interconnection weights, and the network is trained to make proper associations between the inputs and their corresponding outputs (Yeh et al. 1993; Oztas et al. 2006, 1993; Kasperkiewicz et al. 1995). Errors that arise during the learning process can be expressed in terms of mean square error (MSE) and are calculated using Eq. (3).

$$
\operatorname{MSE}=\left(\frac{1}{p}\right) * \sum_{j}(t j-o j)^{2}
$$

In addition, the absolute fraction of variance $\left(R^{2}\right)$ and mean absolute percentage error (MAPE) are calculated using Eqs. (4) and (5), respectively.

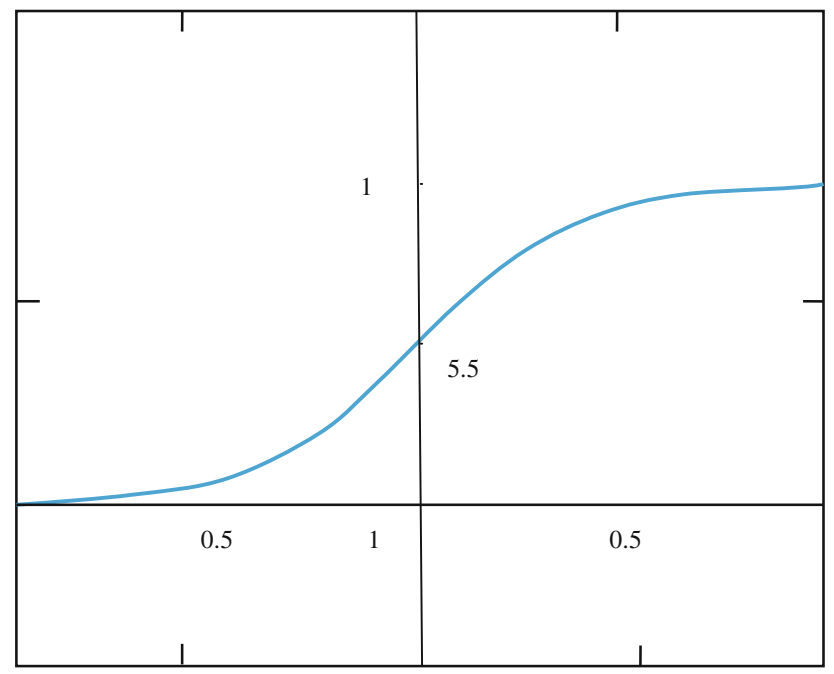

Fig. 6 A graph of a sigmoid function.

$$
\begin{aligned}
& R^{2}=1-\left(\frac{\sum_{j}(t j-o j)^{2}}{\sum_{j}(o j)^{2}}\right) \\
& M A P E=\frac{1}{\mathrm{P}} \sum_{\mathrm{j}}\left(\left|\frac{o j-t j}{o j}\right| * 100\right),
\end{aligned}
$$

where $t j$ is the target value of jth pattern, oj is the output value of $\mathrm{jth}$ pattern, and $p$ is the number of patterns.

\subsection{Input Factors}

The significant factors, cement content, RHA content, percentage of $15 \mathrm{~nm} \mathrm{SiO}$ particles, $80 \mathrm{~nm} \mathrm{SiO}_{2}$ particles content, curing media and curing time were used to describe an ANN model. The model represents a mapping associating these six factors with the permeability properties of ternary blended concrete. The ranges of these input factors, in a total of 38 data sets used in this study. The trained neural network architecture was applicable within this range.

\subsection{Target Vector}

The percentage, velocity and coefficient of water absorption values are the target vector. The range of the percentage, velocity and coefficient of water absorption values are listed in Table 4. The domain of the ANN model to be constructed and was trained. A data set was designated to consist of data in the form of pairs of vectors composed of the six input factors and the associated percentage, velocity and coefficient of water absorption as target vectors. The total data sets (i.e., 174 data sets) for each output were divided into three parts: 140 for training, 17 for validation, and 17 for testing or prediction. The training data sets were used to compute gradient and modernizing weights and biases. The error of the validation sets was monitored during the training procedure to prevent overfitting of training data. The error of the test sets was not used during training, but it was used to compare model's accuracy.

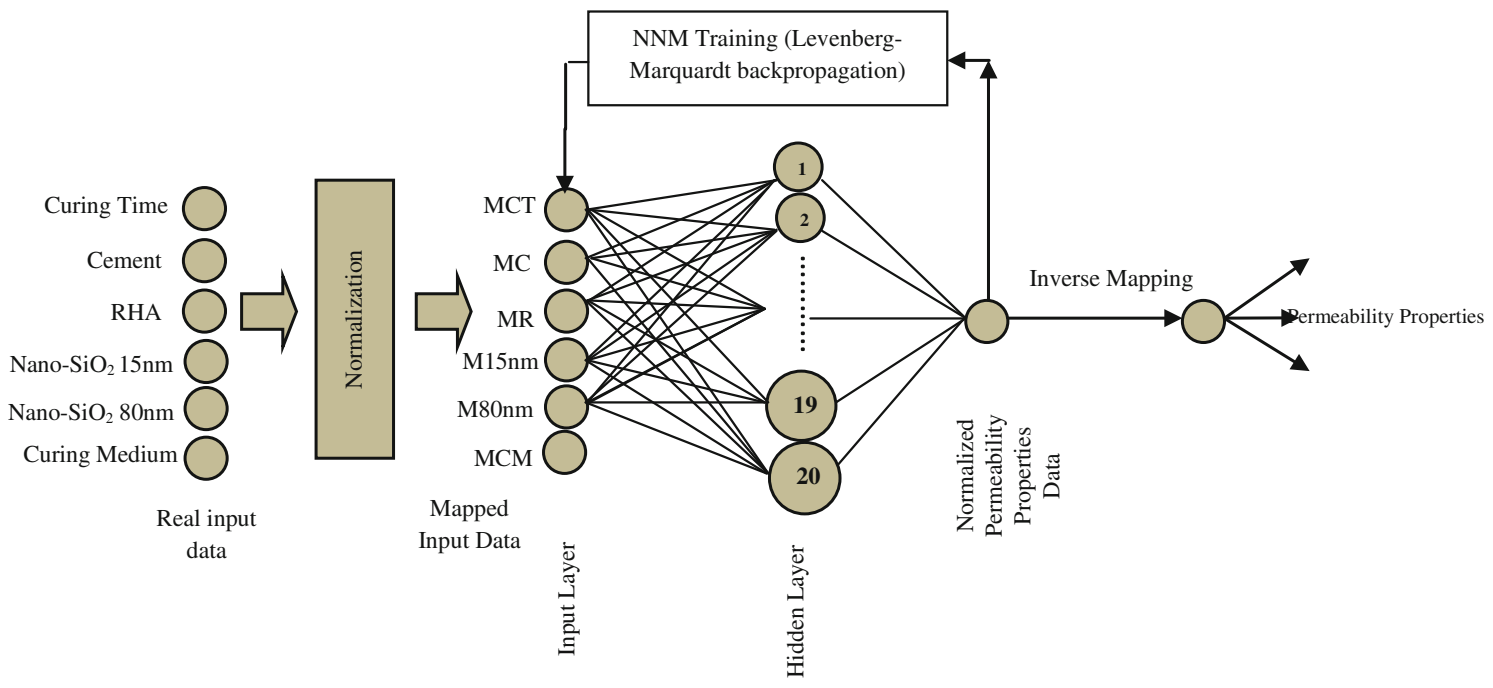

Fig. 7 Schematic of NNM architecture. 


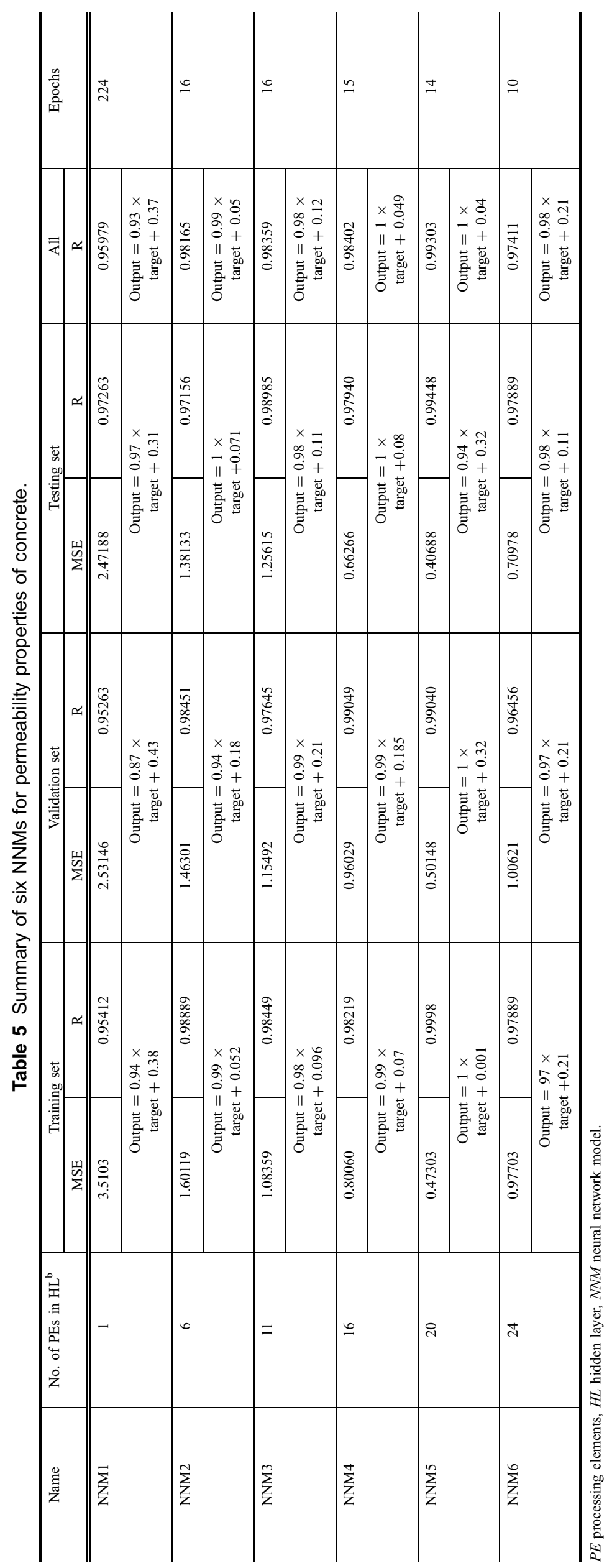



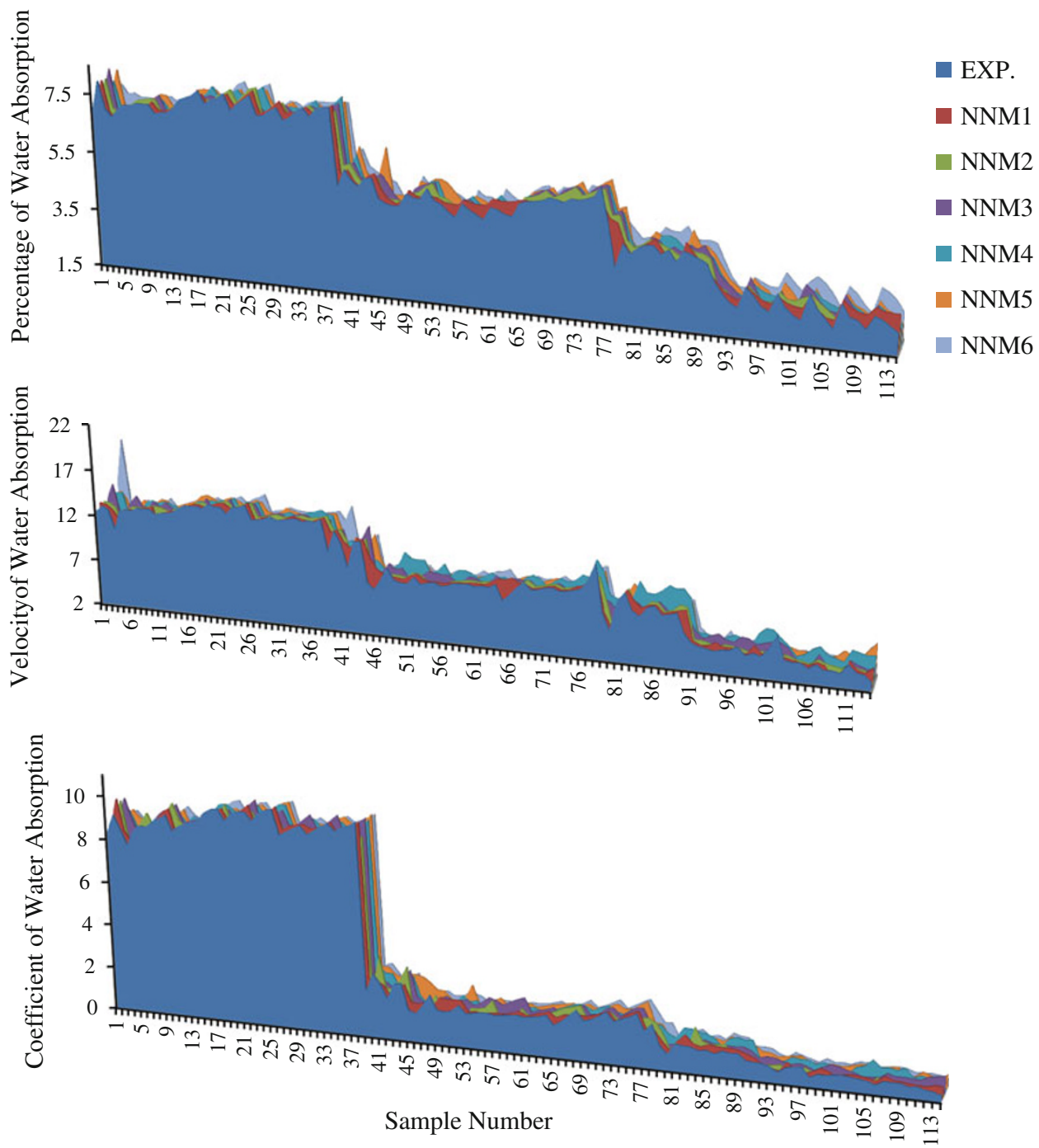

Fig. 8 Comparison of NNMs with experimental results.

\subsection{Training Steps}

As training steps which have been shown in Fig. 5, the input layer takes an input column data contains six parameters and passes it to the hidden layer. Then, the hidden layer maps the input column data to the transfer function witch socalled log-sigmoid and given by Eq. (6):

$$
\sigma(t)=\frac{1}{1+e^{-\beta t}},
$$

where $\beta$ is a slope parameter. This function is called the logsigmoid since a sigmoid can also be constructed using the hyperbolic tangent function rather than this relation, in which case it also can be called a tan-sigmoid. Sigmoid functions are also valued because of their easy calculable derivatives, which is useful for calculating the weight updates in certain training algorithms. The relation is given by Eq. (7):

$$
\frac{d \sigma(t)}{d t}=\sigma(t)[1-\sigma(t)]
$$

In this study, it was referred to the log-sigmoid as simply "sigmoid". The sigmoid function has the property of being parallel to the step function, but by addition of a region of uncertainty. To this end, sigmoid functions were very similar to the input-output interactions of biological neurons, although not exactly the same. A graph of sigmoid function is shown in Fig. 6. Finally, the resulting data were mapped by the linear operation to the outputs of percentage, velocity and coefficient of water absorption by the output layers.

\subsection{Design Algorithm}

The numbers of hidden neurons were found out from a sequential algorithm. At each step of training process, a new feed-forward neural was designed by adding neurons into the hidden layers one by one. The designed NNM was trained using a Levenberg-Marquardt algorithm with MATLAB software's support. LMBP is regularly the fastest existing back-propagation algorithm, and is vastly recommended as a first-choice supervised algorithm, although it needs more memory than other available algorithms. The standard LMBP training process can be described in the simulated code of Fig. 5 (Martys and Ferraris 1997). 

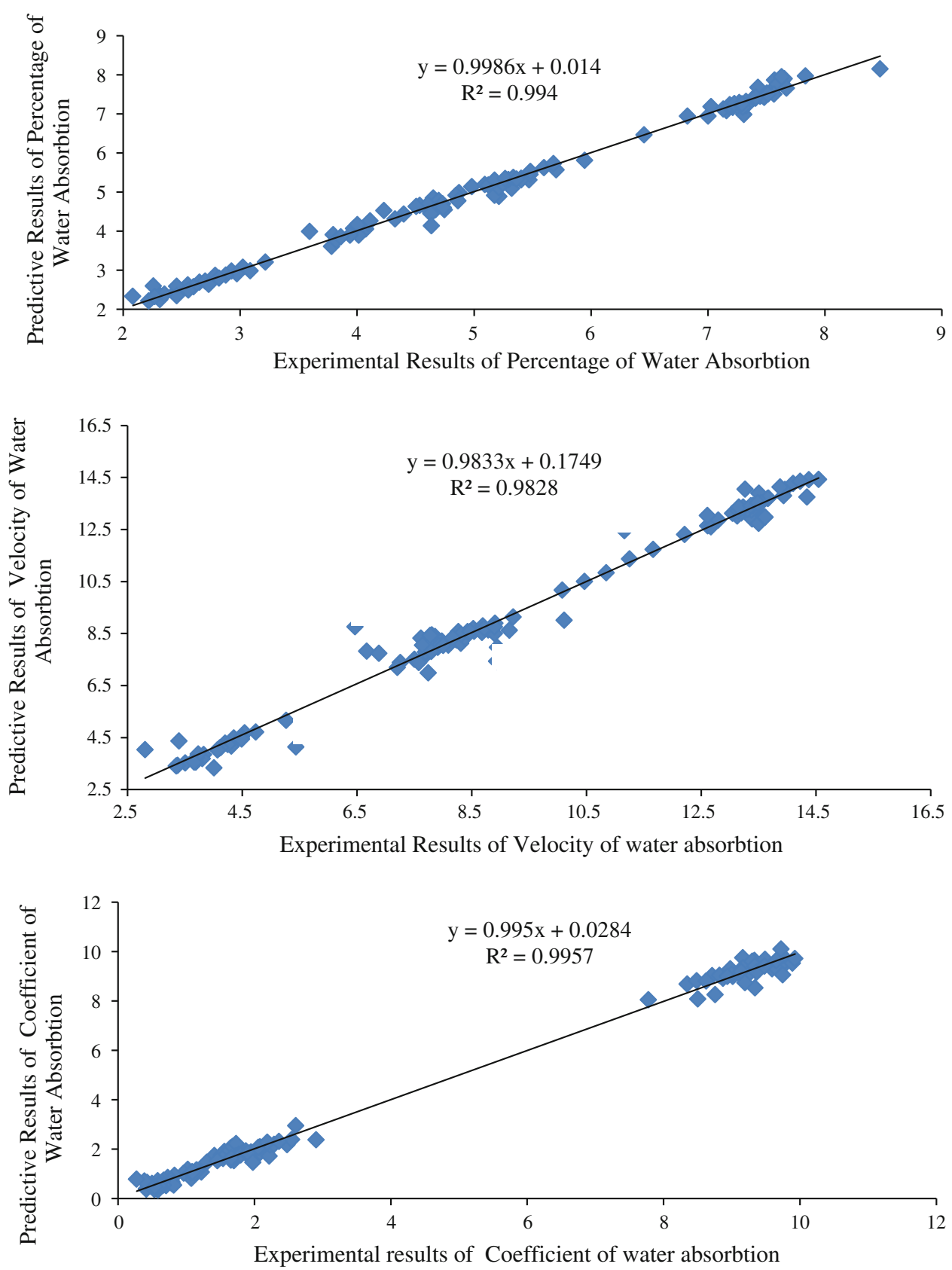

Fig. 9 NNM6 predictions versus experimental results of percentage, velocity and coefficient of water absorption, respectively.

For obtaining the main objective of this paper, three samples of each mix design reported in Table 3 were made and cured at different ages. Totally 522 records gathered by 174 experiments from each percentage, velocity and coefficient of water absorption in accordance to the ASTM C1585 and 642 standards test procedure to construct the training-testing database. For training (interpolation), testing and verification (extrapolation) of the proposed models, 140 and 34 samples were randomly chosen, respectively. The structure of the input-output of the modeler systems were schematically shown in Fig. 7. In this figure, the input parameters are (1) CM, (2) curing time (CT) (3) Cement (C), (4) RHA, (5) $\mathrm{SiO}_{2}$ particles with average diameter of $15 \mathrm{~nm}(15 \mathrm{n})$ and (6) $\mathrm{SiO}_{2}$ particles with average diameter of $80 \mathrm{~nm}(80 \mathrm{n})$ by weight per unit volume of concrete.
Matlab software and its corresponding neural network tools were used to construct and train the proposed NNMs. Table 5 summarizes the architecture of 6 proposed neural networks models in companion with their corresponding validation and test results, means square of error (MSE), number of neurons in hidden layer and their applied epochs.

To make a decision on the ending of the training procedures, two termination statuses were confirmed. Status 1 defines that the training of neural network was ended when the maximum epoch of procedure reached to 1,000 while status 2 defines the training finished when minimum error norm of network obtained. It is clear that the status 2 was preferred termination state. In order to found out the appropriate number of neurons which used in the hidden layer, the number of processing elements (PEs) or neurons was randomly selected to vary from 1 to 24 . For a selected 
configuration, a network was trained six times, and each time, an MSE error and $R$ were calculated on the train, validation and test data sets (Table 5). From Table 5, as it can be seen, the $R$ level of the outputs was increased step-bystep for determining the appropriate number of input nodes in the trial networks. By increasing the number of neurons in the hidden layer up to 20 , the level of $R$ was increased in networks 5 , whereas the use of 24 nodes in the hidden layer does not increase the value of $R$ in networks 6 . For instance NNM1 with one PE in its HL revealed the lowest performance with termination state of 1 ( $R$ of training and testing are 0.95412 and 0.97263 , respectively). While NNM5 which has 20 PEs in its hidden layer was demonstrated the best performance ( $R$ of training and testing are 0.9998 and 0.99448 respectively). It should be mentioned that NNM4 with 16 PEs in its HL presented similar performance with more epochs in contrast with NNM6.

This result could be confirmed by a comparison of NNM findings with respect to the experimental investigations as represented in Fig. 8. Therefore, NNM5 selected as the best neural network for forecasting the percentage, velocity and coefficient of water absorption. Again, $\mathrm{X}-\mathrm{Y}$ plot was used to verify the accuracy of this model as shown in Fig. 9. As it can be seen, more points were well-gathered around the best fit line.

\section{Conclusions}

The experimental results show that laboratory-determined permeability properties of C-NS-RHA ternary blended concrete were correlated with mix design factors and testing parameters and there were six significant factors that affected permeability properties of concrete. These factors are: CM; curing time; percentage of cement; content of RHA; percentage of $15 \mathrm{~nm}$ of $\mathrm{SiO}_{2}$ particles; content of NS particles with average size of $80 \mathrm{~nm}$. Totally 174 concrete mixtures were made, cured and tested from each percentage, velocity and coefficient of water absorption of concrete samples to obtain the permeability properties records. Of these data, 140 data were randomly selected as training sets and the remaining 34 data were used for validation and testing of the model. As it can be seen by increasing the number of neurons in the hidden layer up to 20 , the level of $R$ was increased in network 5 , whereas the use of 24 neurons in the hidden layer does not increase the value of $R$ in networks 6 .

Therefore, ANN5 was selected as the best neural network for predicting the permeability properties of ternary blended concretes. Based on the results mentioned above, it can be concluded that the ANN model is an efficient way of predicting physical properties of concrete. The present study reaffirms that ANN methodology can be used to simulate the problems that are not easily calculable via linear operations and there are not enough theoretical justifications to explain the behavior of the variables involved. Additionally, the model can predict any desired output values, for example the values for concrete properties such as water permeability, based on the instructions it receives in the training stage.
Therefore, the application of the model can save tremendous amount of trial time and energy used for library trials.

On the other hand, since the model was tested against the actual data obtained from experimental results and was found that there is a good agreement between the predicted and actual findings, the applicability of the developed ANN model can be suggested to prediction of similar conditions in the field of engineering.

\section{Open Access}

This article is distributed under the terms of the Creative Commons Attribution License which permits any use, distribution, and reproduction in any medium, provided the original author(s) and the source are credited.

\section{References}

Adhikary, B. B., \& Mutsuyoshi, H. (2006). Prediction of shear strength of steel fiber RC beams using neural networks. Construction and Building Materials, 20(9), 801-811.

Akkurt, S., Ozdemir, S., Tayfur, G., \& Akyol, B. (2003). The use of GA-ANNs in the modeling of compressive strength of cement mortar. Cement and Concrete Research, 33, 973-979.

Alves, M. F., Cremonini, R. A., \& Dal Molin, D. C. C. (2004). A comparison of mix proportioning methods for highstrength concrete. Cement and Concrete Composites, 26(6), 613-621.

Bahia, H. U., Benson, C. H., \& Kanitpong. K. (2001). Hydraulic conductivity (permeability) of laboratory-compacted asphalt mixtures (pp. 25-32). Transportation Research Record 1767. Washington, D.C.: Transportation Research Board.

Caijun, S. (2004). Effect of mixing proportions of concrete on its electrical conductivity and the rapid chloride permeability test (ASTM C1202 or AASHTO 227) results. Cement and Concrete Research, 34, 537-545.

Chindaprasirt, P., Chotithanorm, C., Cao, H. T., \& Sirivivatnanon, V. (2007). Influence of fly ash fineness on chloride penetration of concrete. Construction and Building Materials, 21(2), 356-361.

Ganesan, K., Rajagopal, K., \& Thangavel, K. (2008). Rice husk ash blended cement: Assessment of optimal level of replacement for strength and permeability properties of concrete. Construction and Building Materials, 22(8), $1675-1683$.

Hagan, M., Demuth, H., \& Beale, M. (1996). Neural network design. Boston, MA: PWS Publishing.

Hornik, K., Stinchcombe, M., White, H., \& Auer, P. (1994). Degree of approximation results for feedforward networks approximating unknown mappings and their derivatives. Neural Computation, 6, 1262-1275. 
Ince, R. (2004). Prediction of fracture parameters of concrete by artificial neural networks. Engineering Fracture Mechanics, 71(15), 2143-2159.

Jamil, M., Zain, M. F. M., \& Basri, H. B. (2009). Neural network simulator model for optimization in high performance concrete mix design. European Journal of Scientific Research, 34(1), 61-68.

Kasperkiewicz, J., Racz, J., \& Dubrawski, A. (1995). HPC strength prediction using artificial neural networks. Journal of Computing in Civil Engineering, 9(4), 279-284.

Martys, N. S., \& Ferraris, C. F. (1997). Capillary transport in mortars and concrete. Cement and Concrete Research, 27(5), 747-760.

Metha, P. K., \& Artcin, P. C. (1990). Principles underlying the production of high-performance concrete. Cement, Concrete and Aggregates, 12(2), 70-78.

Monteiro, P. J. M., \& Mehta, P. K. (1986). Improvement of the aggregate cement paste transition zone by grain refinement of hydration product. In Proceedings of the VIIIth international congress on the chemistry of cement, Vol. 2, Riode-Jeneiro, Brazil, pp. 433-437.

Naji Givi, A., Abdul Rashid, S., Aziz, F. N. A., \& Salleh, M. A. M. (2010a). Assessment of the effects of rice husk ash particle size on strength, water permeability and workability of binary blended concrete. Construction and Building Materials, 24(11), 2145-2150.

Naji Givi, A., Abdul Rashid, S., Aziz, F. N. A., \& Salleh, M. A. M. (2010b). Experimental investigation of the size effects of $\mathrm{SiO}_{2}$ nano-particles on the mechanical properties of binary blended concrete. Composites: Part B. doi: 10.1016/j.compositesb.2010.08.003

Neville, A. M. (1995). Properties of concrete (4th ed.). Essex, U.K.: Longman Group Limited.

Oztas, A., Pala, M., Ozbay, E., Kanca, E., Çagar, N., \& Bhatti, M. A. (2006). Predicting the compressive strength and slump of high strength concrete using neural networks. Construction and Building Materials, 21(2), 384-394.

Pala, M., Ozbay, E., Öztaş, A., \& Yuce, M. I. (2007a). Appraisal of long term effects of fly ash and silica fume on compressive strength of concrete by neural networks. Construction and Building Materials, 20(9), 769-775.

Pala, M., Ozbay, E., Öztaş, A., \& Yuce, M. I. (2007b). Appraisal of long-term effects of fly ash and silica fume on compressive strength of concrete by neural networks. Construction and Building Materials, 21(2), 384-394.

Parichatprecha, R., \& Nimityongskul, P. (2009). Analysis of durability of high performance concrete using artificial neural networks. Construction and Building Materials, 23, 910-917.

Philleo, R. E. (1986). Freezing and thawing resistance of highstrength concrete. CNHRP Synthesis of Highway Practice, 129. Washington, D.C.: Transportation Research Boards.

Powers, T. C. (1968). Properties of fresh concrete. New York, NY: Wiley.
Powers, T. C., Copeland, L. E., \& Mann, H. M. (1959). Capillary continuity or discontinuity in cement paste. Journal of the PCA Research and Development Laboratories, 1(2), 38-48.

Prabir, B. C. (2001). High performance concrete: mechanism and application. ICI Journal, 2(1), 15-38.

Ransinchung, G. D., Kumar, B., \& Kumar, V. (2009). Assessment of water absorption and chloride ion penetration of pavement quality concrete admixed with wollastonite and microsilica. Construction and Building Materials, 23(2), 1168-1177.

Rumellhert, D., Hinto, G., \& Williams, R. (1986). Learning internal representations by error propagation. Cambridge, MA: MIT Press.

Sirivivatnanon, V., \& Cao, H. T. (1998). Binder dependency of durability properties of HPC. In Canadian international symposium of HPC and reactive powder concrete, Canada, pp. $227-240$.

Sobhani, J., et al. (2010). Prediction of the compressive strength of no-slump concrete: A comparative study of regression, neural network and ANFIS models. Construction and Building Materials, 24(5), 709-718.

Tasdemir, C. (2003). Combined effects of mineral admixtures and curing conditions on the sorptivity coefficients of concrete. Cement and Concrete Research, 33, 1637-1642.

Topçu, I. B., \& Sarıdemir, M. (2007). Prediction of properties of waste AAC aggregate concrete using artificial neural network. Computational Materials Science, 41(1), 117-125.

Topçu, I. B., \& Sarıdemir, M. (2008a). Prediction of rubberized concrete properties using artificial neural network and fuzzy logic. Construction and Building Materials, 22(4), 532-540.

Topçu, I. B., \& Sarıdemir, M. (2008b). Prediction of compressive strength of concrete containing fly ash using artificial neural network and fuzzy logic. Computational Materials Science, 41(3), 305-311.

Wee, T. H., Suryavanshi, J. A., \& Tin, S. S. (2000). Evaluation of rapid chloride permeability test (RCPT) results for concrete containing mineral admixtures. ACI Materials Journal, 97(2), 221-232.

Yeh, I. C. (1999). Design of high-performance concrete mixture using neural networks and nonlinear programming. Journal of Computing in Civil Engineering, 13(1), 36-42.

Yeh, Y. C., Kuo, Y. H., \& Hsu, D. H. (1993). Building KBES for diagnostic PC Pile with ANN. Journal of Computing in Civil Engineering, 7, 71-93.

Zain, M. F. M., Islam, M. N., \& Basri, I. H. (2005). An expert system for mix design of high performance concrete. Advances in Engineering Software, 36, 325-377.

Zhao, T. J., Zhou, Z. H., Zhu, J. Q., \& Feng, N. Q. (1998). An alternating test method for concrete permeability. Cement and Concrete Research, 28, 7-12. 